\title{
Impact of doping and MOCVD conditions on minority carrier lifetime of zinc- and carbon-doped InGaAs and its applications to zinc- and carbon-doped InP/InGaAs heterostructure bipolar transistors
}

\author{
Delong Cui, Seth M Hubbard, Dimitris Pavlidis, \\ Andreas Eisenbach and Cyril Chelli \\ Department of Electrical Engineering and Computer Science ${ }^{1}$, The University of Michigan, \\ Ann Arbor, MI, USA \\ E-mail: pavlidis@umich.edu
}

Received 28 August 2001, in final form 5 March 2002

Published 9 May 2002

Online at stacks.iop.org/SST/17/503

\begin{abstract}
The impact of doping and metalorganic chemical vapour deposition growth conditions on the minority carrier lifetime of zinc- and carbon-doped InGaAs is reported. Room temperature photoluminescence measurements have been employed to obtain direct information on the non-radiative lifetime of the materials. Low growth temperature and low V/III ratio lead to the lower carrier lifetime of the carbon-doped InGaAs samples. InP/InGaAs heterostructure bipolar transistors were grown and fabricated using both zinc- and carbon-doped InGaAs layers as the base regions. The current gain values measured for these devices agree well with the values calculated from the carrier lifetime and mobility/diffusion coefficient measurements.
\end{abstract}

\section{Introduction}

Using carbon doping for p-type InGaAs is very attractive for high performance $\mathrm{InP} / \mathrm{InGaAs}$ heterostructure bipolar transistors (HBTs) due to its low diffusivity and high degree of incorporation compared with traditionally used dopants such as Zn and Be. We have previously reported [1] on the successful growth of heavily carbon-doped p-type InGaAs by using metalorganic chemical vapour deposition (MOCVD). However, carbon is of amphoteric nature in InGaAs. It behaves as either donor or acceptor depending on whether carbon occupies a group III or group V site. Low growth temperature and low $\mathrm{V} / \mathrm{III}$ ratio are necessary to realize p-type doping. This may degrade the material quality and some of the important characteristics, such as minority carrier lifetime, which directly dictates the current gain $(\beta)$ of $\mathrm{InP} / \mathrm{InGaAs}$ HBTs. It is, therefore, of great interest to study the effect

\footnotetext{
1 URL: http://www.eecs.umich.edu/dp group/
}

of low growth temperature/low V/III ratio on the minority carrier lifetime of carbon-doped InGaAs.

Photoluminescence (PL) measurements have emerged in recent years as a fast and non-invasive tool for the analysis and quality control of compound semiconductor materials and technology. The room temperature (RT) PL used in this work permits evaluation of the minority carrier lifetime of carbonand zinc-doped InGaAs samples. The technique is based on PL measurements performed at different excitation levels [2-5]. The measured data, plotted as a function of excitation, are then fitted to a simple theoretical model of the PL emission by considering the linear and quadratic regime of this dependence in order to extract the minority carrier lifetime.

We have recently reported on a first comparative study of carrier lifetime in MOCVD-grown zinc- and carbondoped InGaAs [6]. Room temperature PL measurements were used to investigate and characterize carrier lifetime of zinc- and carbon-doped layers with a wide range of doping concentrations. It was found that the carrier lifetime of carbon-doped InGaAs is almost one magnitude lower 
than that of zinc-doped InGaAs samples. In this paper we provide further details on material properties such as Hall mobility, background doping concentration, as well as source incorporation efficiency, affected by MOCVD growth conditions such as low growth temperature. We also report on the PL properties of heavily strained carbondoped InGaAs, the minority carrier lifetime dependence in measurement temperature and the Auger coefficients of zincand carbon-doped InGaAs. The current gains of HBTs employing zinc- and carbon-doped base layers have been estimated using the measured carrier lifetime results combined with mobility/diffusion constant characteristics. InP/InGaAs HBTs utilizing both zinc- and carbon-doped InGaAs as base regions have been grown and fabricated. It is shown that the measured current gain values agree well with those evaluated from carrier lifetime measurements.

\section{Experiments}

\subsection{Growth of zinc-and carbon-doped InGaAs}

The InGaAs samples were grown in an EMCORE GS3200 LP-MOCVD system in a vertical mass transport reactor with a rotating susceptor. TMIn and TMGa were used as In and Ga sources, respectively. Pure arsine and phosphine were used for the group $\mathrm{V}$ elements. Liquid $\mathrm{CBr}_{4}$ and $\mathrm{DeZn}$ were used as carbon and zinc precursor, respectively. The pressure of the growth chamber was maintained to be 60 Torr and the susceptor was rotated at $100 \mathrm{rpm}$ to provide the best sample uniformity. All growth experiments were carried out on Fedoped semi-insulating (001) InP substrates.

In order to achieve highly carbon-doped p-type InGaAs by MOCVD growth, a low growth temperature and a low V/III ratio are required [7-9]. A growth temperature of $450{ }^{\circ} \mathrm{C}$ was used for the heavily p-type carbon-doped InGaAs $\left(10^{18}\right.$ $10^{19} \mathrm{~cm}^{-3}$ ) to provide the best trade-off between the doping concentration and surface morphology. Higher growth temperatures $\left(530{ }^{\circ} \mathrm{C}\right)$ were used for low and medium $\mathrm{p}$ doping concentrations $\left(10^{16}-10^{17} \mathrm{~cm}^{-3}\right)$ in order to improve the material quality and surface morphology. This temperature approaches the highest limit where p-type InGaAs can be obtained using $\mathrm{CBr}_{4}$ as a carbon precursor. The zincdoped InGaAs samples were grown at an optimized growth temperature of $570{ }^{\circ} \mathrm{C}$. In order to investigate the effect of the growth temperature and dopant type, zinc-doped samples were also grown at $450{ }^{\circ} \mathrm{C}$.

Figure 1 shows the background doping concentration, as well as the Hall mobility of InGaAs layer as a function of MOCVD growth temperature. The background doping concentration increases and the Hall mobility decreases dramatically as expected when the growth temperature decreases from the optimized MOCVD growth temperature $\left(570{ }^{\circ} \mathrm{C}\right)$. For example, the Hall mobility of unintentionally doped InGaAs decreases from $11000 \mathrm{~cm}^{2} \mathrm{~V}^{-1} \mathrm{~s}^{-1}$ to below $2000 \mathrm{~cm}^{2} \mathrm{~V}^{-1} \mathrm{~s}^{-1}$ when the growth temperature decreases from $570{ }^{\circ} \mathrm{C}$ to $430^{\circ} \mathrm{C}$. This trend is associated with the difficulty in good quality layer growth at low temperatures caused by the decreased source incorporation efficiency, especially TMGa below $450{ }^{\circ} \mathrm{C}$. As a result, the material quality is degraded, as can be seen by the high background doping concentration

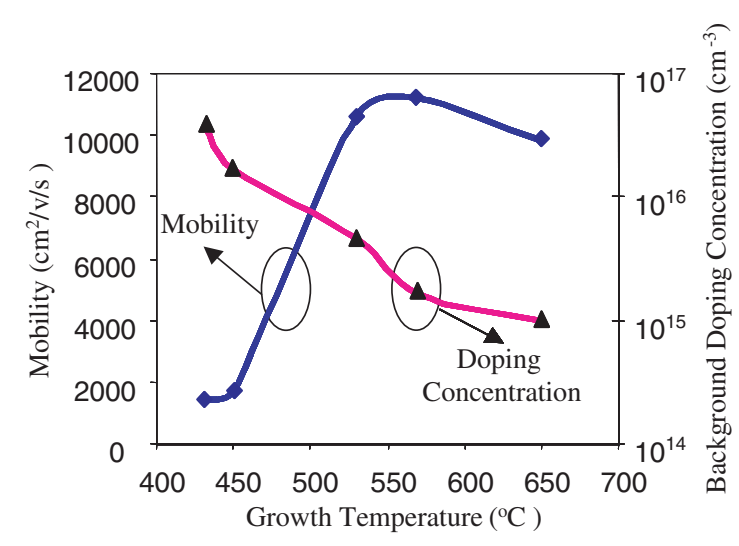

Figure 1. Mobility and background doping concentration of unintentionally doped InGaAs at different growth temperatures.

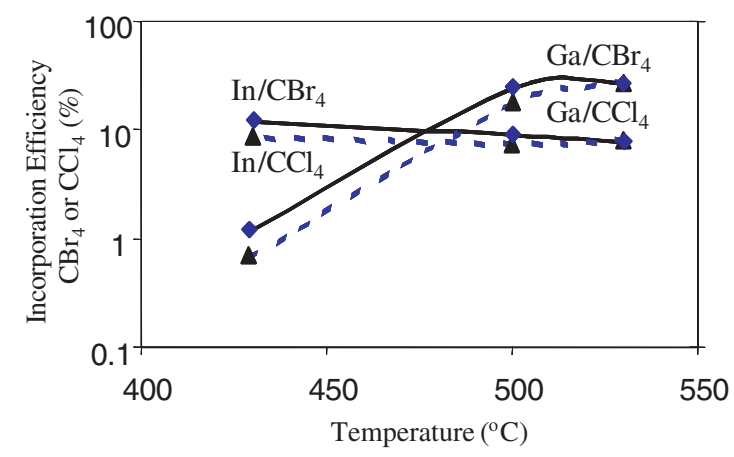

Figure 2. The change of incorporation efficiency of TMIn and TMGa with MOCVD growth temperature with and without the presence of $\mathrm{CBr}_{4} / \mathrm{CCl}_{4}$. (The incomplete depletion of TMGa below $500{ }^{\circ} \mathrm{C}$ causes the rapid decrease of incorporation efficiency. The further reduction of incorporation efficiency in the presence of $\mathrm{CBr}_{4} / \mathrm{CCl}_{4}$ is caused by etching of InAs and $\mathrm{GaAs}$ and the elimination of TMIn and TMGa sources by gas phase reaction with $\mathrm{CBr}_{4} / \mathrm{CCl}_{4}$ at the growth front.)

and low Hall mobility for samples grown at low growth temperature.

The incorporation efficiency of TMGa can be further decreased in the presence of $\mathrm{CBr}_{4}$ precursor. Figure 2 shows the incorporation efficiency as a function of growth temperature with and without $\mathrm{CBr}_{4}$. The rapid decrease of incorporation efficiency of TMGa in the absence of $\mathrm{CBr}_{4}$ below $500{ }^{\circ} \mathrm{C}$ is due to the incomplete depletion of TMGa. As can be seen, in the presence of $\mathrm{CBr}_{4}$, the TMGa and TMIn incorporation efficiencies are further reduced. This is caused by the etching of InAs and GaAs and the elimination of TMIn and TMGa sources by gas phase reaction with $\mathrm{CBr}_{4}$ at the growth front. All of the above effects lead to a disturbed alloy composition, as well as the reduced growth rate. It is therefore expected that the material quality degrades as the growth temperature is lowered.

\subsection{Measurements}

Depending on the samples, the PL experiments were carried out from RT to $10 \mathrm{~K}$. The PL measurements were performed using an Ar-ion laser with a maximum power of $150 \mathrm{~mW}$. The PL spectrum was detected with an extended wavelength InGaAs detector using a SPEX $500 \mathrm{M}$ monochromator. 
Impact of doping and MOCVD conditions on minority carrier lifetime of zinc- and carbon-doped InGaAs

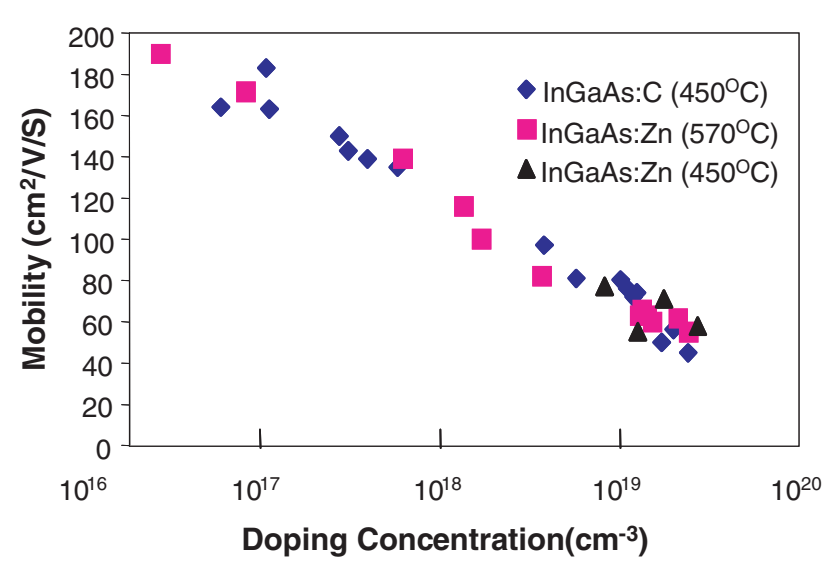

Figure 3. Hall mobility as a function of doping concentration and growth temperature of InGaAs:C and InGaAs:Zn samples.

To reduce the intensity of the laser, different neutral density filters were used with various transmissions. The data obtained were plotted and treated according to the theory [2-5] in order to extract the carrier lifetime.

All the double crystal x-ray data reported in this study were obtained from a Rigaku double-crystal diffractometer with a conventional $1.5 \mathrm{~kW}$ generator fitted with a $\mathrm{Cu}$ target $\left(\lambda_{\mathrm{Cu}} \mathrm{K}_{\alpha 1}=0.1540562 \mathrm{~nm}\right)$. X-ray diffraction curves were recorded in the vicinity of the (004) reflection.

\section{Results and discussion}

\subsection{Hall measurements and mobility of zinc-and carbon-doped InGaAs samples}

Doping concentration and mobility of zinc- and carbon-doped InGaAs samples were measured by using Hall measurements. Zinc-doped InGaAs samples were grown both at $570{ }^{\circ} \mathrm{C}$ and $450{ }^{\circ} \mathrm{C}$ in order to see the effects of low growth temperature. Figure 3 shows the Hall mobility as a function of doping concentration for both zinc- and carbon-doped samples. As can be seen, the Hall mobility decreases as the doping concentration increases for both types of samples. Despite the low temperature and low V/III ratio used for carbondoped InGaAs layer growth in order to improve the carbon incorporation efficiency, the Hall mobility of carbon-doped samples is approximately the same as that of zinc-doped samples over the entire doping range. It is also noted that there is little impact on Hall mobility values as the growth temperature decreases from $570{ }^{\circ} \mathrm{C}$ to $450{ }^{\circ} \mathrm{C}$.

\subsection{Studies of PL spectrum versus measurement temperature for heavily strained carbon-doped InGaAs}

Figure 4 shows the PL spectra of a heavily strained ( $\Delta a / a=$ $1.6 \times 10^{-3}$ from double-crystal x-ray diffraction (DXRD) measurements) carbon-doped InGaAs sample grown at $450{ }^{\circ} \mathrm{C}$ with a doping concentration of $5 \times 10^{18} \mathrm{~cm}^{-3}$. The PL spectrum shows that the main peak shifts towards lower wavelengths as the temperature decreases (from $1.8 \mu \mathrm{m}$ at RT to $1.65 \mu \mathrm{m}$ at $10 \mathrm{~K}$ ) due to the temperature dependence of the bandgap.

At very low temperatures, the PL spectrum yields two peaks, which can be associated with the valence band

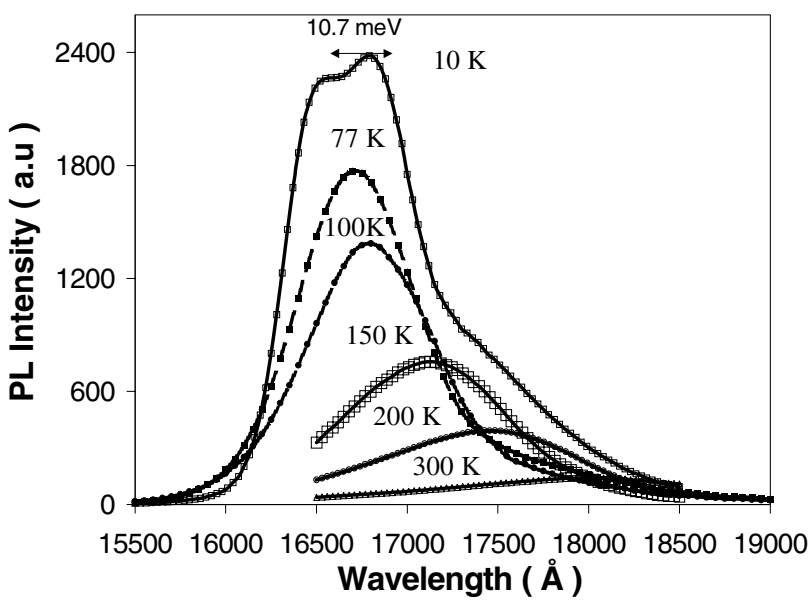

Figure 4. PL versus temperature for heavily stained InGaAs:C sample.

splitting into light-hole and heavy-hole resulting in both conduction band to light-hole and conduction band to heavyhole transitions [10]. The biaxial strain effect on $E_{\mathrm{g}}$ can be decomposed into hydrostatic strain which shifts the bandgap and uniaxial strain which splits the two valence band edges at $k=0$. The measured energy splitting of $10.7 \mathrm{meV}$ can be used to calculate the lattice mismatch $\Delta a / a$, by using the perturbative analysis of Asai and Oe [11] and the material parameters of Gaskill et al [12]:

$$
\begin{gathered}
\Delta E\left(\frac{3}{2}, \pm \frac{1}{2}\right)=-(7.250+3.476) \varepsilon_{\|}, \\
\Delta E\left(\frac{3}{2}, \pm \frac{3}{2}\right)=-(7.250-3.476) \varepsilon_{\|}
\end{gathered}
$$

where the first term in the brackets refers to the hydrostatic strain and the second term to the uniaxial strain, and $\varepsilon_{7}=$ $-\Delta a / a$ [13]. An analysis of the results shows that $\Delta a / a$ is about $1.5 \times 10^{-3}$, which is in good agreement with DXRD measurements $\left(1.6 \times 10^{-3}\right)$. The energy bandgap measured at $300 \mathrm{~K}$ for this carbon-doped InGaAs sample $\left(5 \times 10^{18} \mathrm{~cm}^{-3}\right)$ is $688.1 \mathrm{meV}$. The PL spectrum for an undoped $\left(3 \times 10^{15} \mathrm{~cm}^{-3}\right)$ lattice-matched InGaAs sample was also measured and the luminescence peak position was at $746.7 \mathrm{meV}$, which is in excellent agreement with published results [10, 14-16].

\subsection{Estimation of carrier lifetime for zinc- and carbon-doped InGaAs samples}

Figure 5 shows typical curves for PL intensity versus laser intensity $(I)$ for zinc- and carbon-doped InGaAs. For carbonand zinc-doped InGaAs samples with doping concentrations of $4.7 \times 10^{18} \mathrm{~cm}^{-3}$ and $4.5 \times 10^{18} \mathrm{~cm}^{-3}$, respectively, a large difference can be observed, indicating a shorter lifetime in carbon-doped InGaAs.

In order to obtain absolute carrier lifetime values, some samples were measured at the Centre National d' Etudes des Telecommunications (CNET, France) using time-resolved PL to establish a carrier lifetime reference to which all other samples could be compared.

Figure 6 shows that zinc-doped $\operatorname{InGaAs}$ has an approximately ten times higher carrier lifetime than carbondoped InGaAs at the same doping level. As an example, for the doping concentration of $2.14 \times 10^{19} \mathrm{~cm}^{-3}$, the zinc-doped 


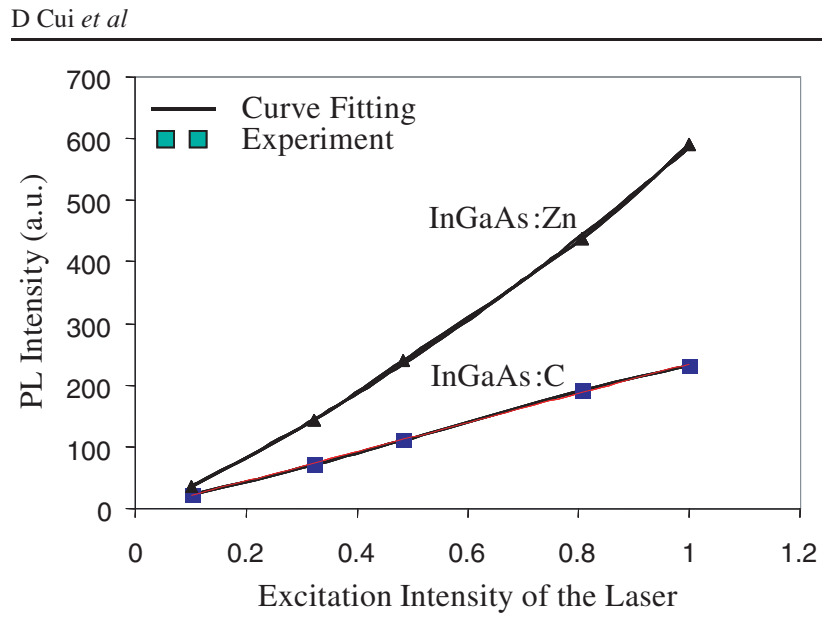

Figure 5. Typical experimental relationship between PL intensity and excitation density.

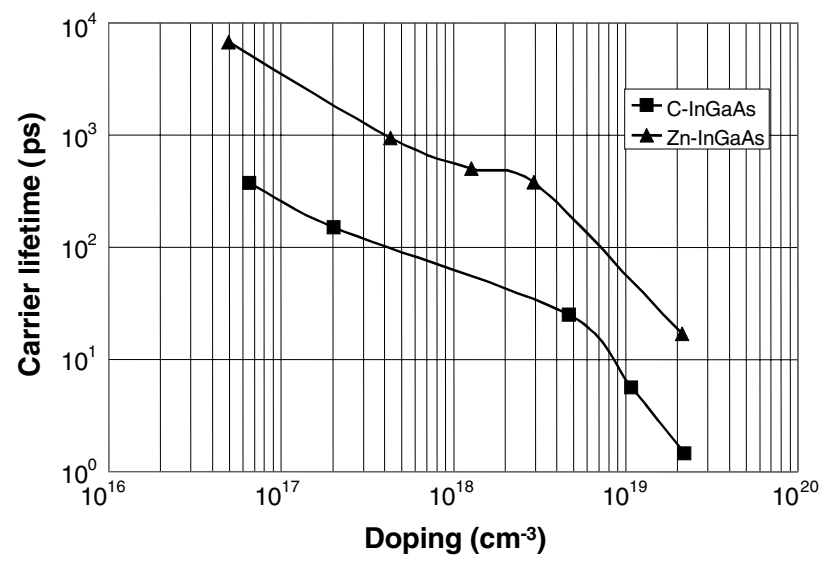

Figure 6. Comparison of minority carrier lifetime between InGaAs: C and InGaAs: $\mathrm{Zn}$ (carrier lifetime of zinc-doped InGaAs is approximately ten times higher than that of carbon-doped InGaAs at the same doping level).

sample has a minority lifetime of $16.8 \mathrm{ps}$ while the carbondoped $\left(2.26 \times 10^{19} \mathrm{~cm}^{-3}\right)$ sample has a value of $1.65 \mathrm{ps}$. The lower minority lifetime in the carbon-doped sample may be due to low growth temperature and low V/III ratio during growth.

To gain a better insight into the above trends, the effect of growth temperature on minority carrier lifetime was investigated by measuring zinc-doped InGaAs samples grown at $450{ }^{\circ} \mathrm{C}$. A comparison of the PL spectra of zinc-doped samples grown at $570{ }^{\circ} \mathrm{C}$ and $450{ }^{\circ} \mathrm{C}$ is shown in figure $7(a)$. The spectra indicate a better quality for the samples grown at $570{ }^{\circ} \mathrm{C}$. Figure $7(b)$ shows the carrier lifetime data of zincdoped samples grown at both $570{ }^{\circ} \mathrm{C}$ and $450{ }^{\circ} \mathrm{C}$ as well as those of carbon-doped InGaAs samples. The carrier lifetime for zinc-doped samples grown at $450{ }^{\circ} \mathrm{C}$ is lower than that grown at $570{ }^{\circ} \mathrm{C}(56.7 \mathrm{ps}$ versus $202 \mathrm{ps})$ for approximately the same doping concentration $\left(\sim 4 \times 10^{18} \mathrm{~cm}^{-3}\right)$. This is also an indication of the degradation of the material quality as the growth temperature decreases. Moreover, for nearly the same doping concentration and the same growth temperature $\left(450{ }^{\circ} \mathrm{C}\right)$, a minority carrier lifetime of $25 \mathrm{ps}$ is found for carbon-doped InGaAs $\left(4.7 \times 10^{18} \mathrm{~cm}^{-3}\right)$ compared to $56 \mathrm{ps}$ for zinc-doped InGaAs $\left(4.5 \times 10^{18} \mathrm{~cm}^{-3}\right)$. The difference of minority carrier lifetime between these two samples is believed

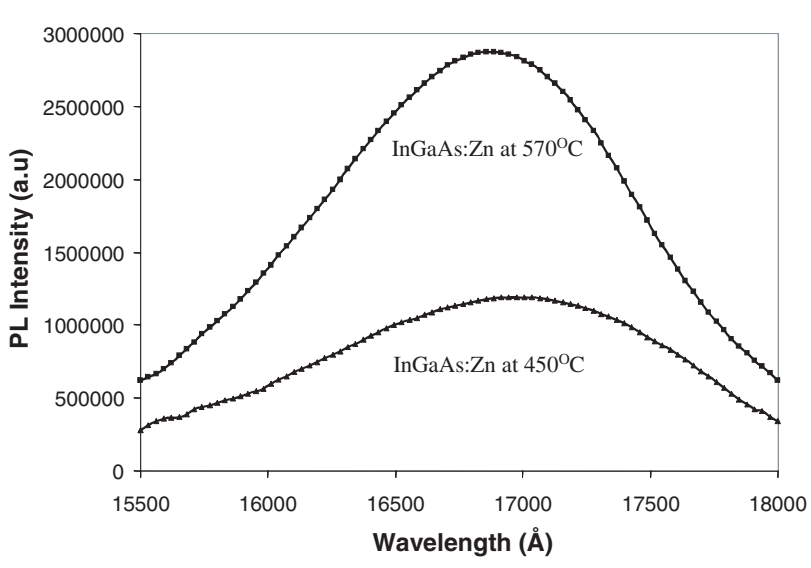

(a)

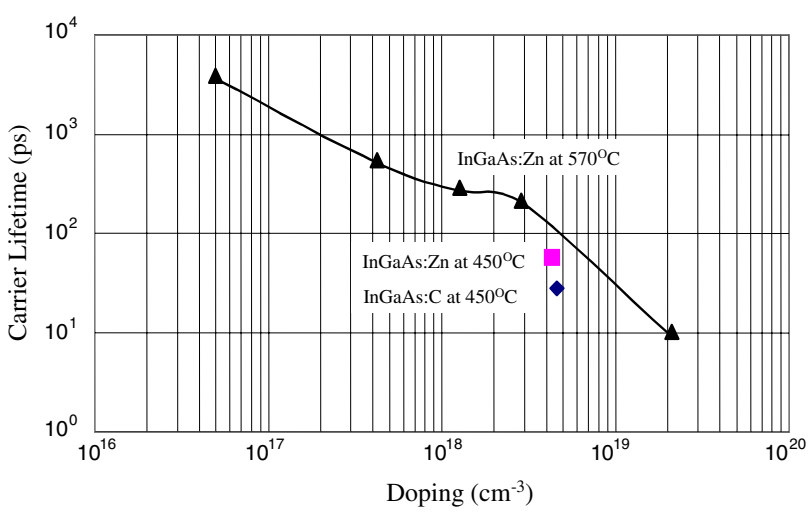

(b)

Figure 7. (a) PL intensity for InGaAs:Zn samples grown at different temperatures. (b) Comparison of carrier lifetime for InGaAs:Zn samples grown at different temperatures.

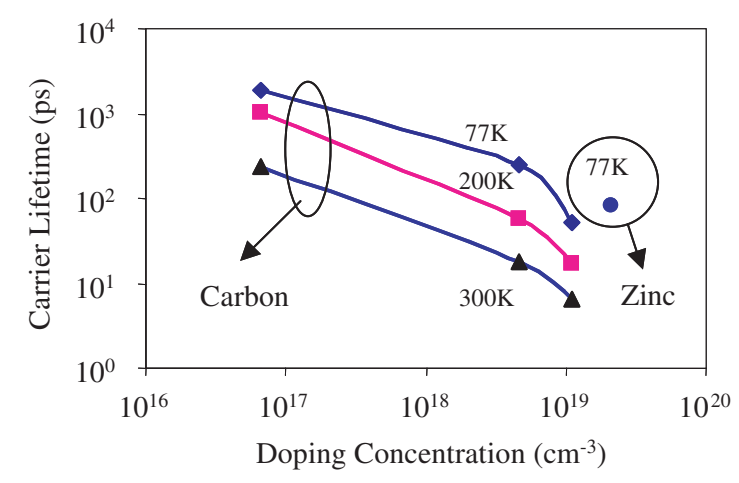

Figure 8. Carrier lifetime of InGaAs:C as a function of doping concentration at different measurement temperatures.

to be due to the fact that lower V/III ratio is used for carbondoped InGaAs growth in order to ensure p-type doping. The hydrogen passivation of carbon atoms may also be responsible for the low minority carrier lifetime in carbon-doped InGaAs samples.

Figure 8 shows the carrier lifetime measurements for carbon-doped InGaAs samples under different measurement temperatures. One can see that the carrier lifetime of carbon- and zinc-doped InGaAs increases as the measurement temperature decreases. For example, at a doping concentration of $1.1 \times 10^{19} \mathrm{~cm}^{-3}$, the carbon-doped sample has a minority 


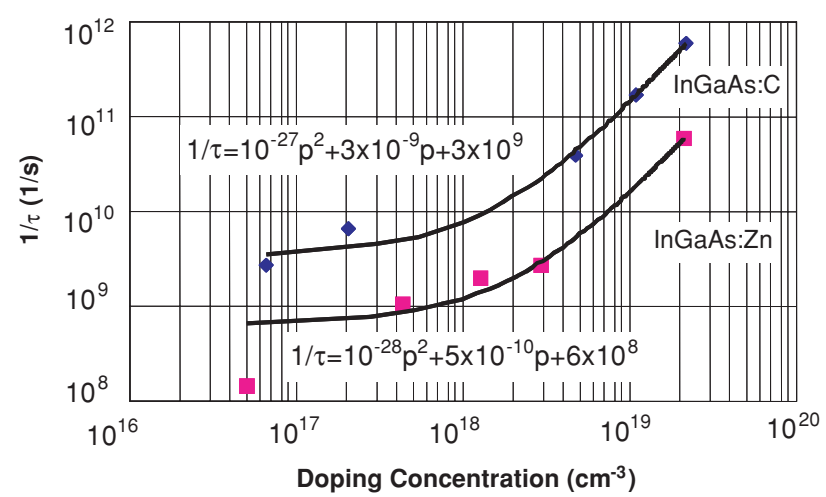

Figure 9. $1 / \tau$ versus doping concentration for both InGaAs:C and InGaAs:Zn.

lifetime of 6.4 ps at $300 \mathrm{~K}$ and $52 \mathrm{ps}$ at $77 \mathrm{~K}$. On the other hand, at a doping concentration of $2.14 \times 10^{19} \mathrm{~cm}^{-3}$, the zinc-doped sample has a minority lifetime of 16.8 ps at $300 \mathrm{~K}$ and $82.6 \mathrm{ps}$ at $77 \mathrm{~K}$. This is, as expected, due to the more pronounced freeze out of impurities and recombination centres at low measurement temperature. The results also show that the carrier lifetime saturates for low temperature measurement at high doping concentrations.

\subsection{Auger recombination study for zinc-and carbon-doped InGaAs}

In highly doped samples, the carrier lifetime is mainly controlled by Auger recombination. The experimental minority carrier lifetime $(\tau)$ results can be fitted to an empirical relation for bulk recombination as

$$
\frac{1}{\tau}=C_{0}+C_{1} p+C_{2} p^{2}
$$

where $p$ is the doping concentration and $C_{0}, C_{1}, C_{2}$ are the constant coefficients.

As can be seen from equation (2), the Auger recombination coefficient $C_{2}$ dominates as the doping concentration exceeds a certain level. Figure 9 shows the reciprocal of carrier lifetime as a function of doping concentration. The Auger recombination coefficient $C_{2}$ can be estimated by fitting the results with equation (2). $C_{2}$ values of $10^{-28} \mathrm{~cm}^{6} \mathrm{~s}^{-1}$ for zinc-doped InGaAs and of $10^{-27} \mathrm{~cm}^{6} \mathrm{~s}^{-1}$ for carbon-doped InGaAs were found using this approach. This indicates almost an order of magnitude difference in terms of carrier lifetime for zinc- and carbon-doped InGaAs samples.

The measured carrier lifetime can be used to extract the gain $(\beta)$ of HBTs using the following equation

$$
\beta=\frac{\tau_{\text {base_lifetime }}}{\tau_{\text {transit }}}
$$

where the base transit time can be calculated using

$$
\tau_{\text {transit }}=\frac{W_{B}^{2}}{2 D}
$$

and $W_{B}$ is the base width and $D$ is the diffusion coefficient.

To calculate the base transit time, the diffusion coefficient $D$ can be estimated from the Einstein relationship by using the mobility values measured by Hall measurements. InGaAs

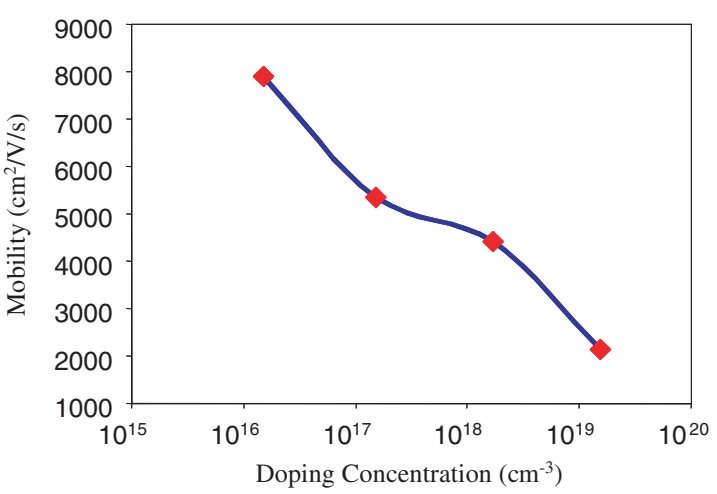

Figure 10. Mobility of InGaAs as a function of doping concentration.

samples with different doping concentrations have been grown and characterized by Hall measurements. It should be noted that, for p-type base, the minority carriers are electrons, therefore n-type-doped InGaAs were used to characterize the electron diffusion coefficient, assuming of course that the electron diffusion constant is the same in n-type material (majority carriers) as in p-type material (minority carriers). Figure 10 shows the Hall mobility (majority carriers) as a function of doping concentration for n-type InGaAs. As can be seen, InGaAs material grown in this study has a mobility of $2200 \mathrm{~cm}^{2} \mathrm{~V}^{-1} \mathrm{~s}^{-1}$ at a doping concentration of $2 \times 10^{19} \mathrm{~cm}^{-3}$, corresponding to a diffusion coefficient $D$ of $55 \mathrm{~cm}^{2} \mathrm{~s}^{-1}$ as calculated from the Einstein relationship.

Little information exists in the literature about minority carrier diffusion coefficient values. An electron (minority carrier) diffusion length $L$ of $0.4-0.6 \mu \mathrm{m}$ has been reported by Ambree et al at a doping concentration of $2 \times 10^{19} \mathrm{~cm}^{-3}$ $[18,19]$. As will be shown next, this is close to the values estimated in this work. The diffusion length can be related to diffusion coefficient $(D)$ by

$$
L=\sqrt{D \tau}
$$

where $D$ is the diffusion coefficient, $L$ is the diffusion length and $\tau$ is the minority carrier lifetime. Using the above diffusion coefficient $D$ of $55 \mathrm{~cm}^{2} \mathrm{~s}^{-1}\left(2 \times 10^{19} \mathrm{~cm}^{-3}\right)$ calculated from the Einstein relationship and measured minority carrier lifetime of $17 \mathrm{ps}$ (zinc-doped InGaAs at $2.1 \times 10^{19} \mathrm{~cm}^{-3}$ ), one can get the diffusion length of $0.3 \mu \mathrm{m}$ at a doping concentration of $2 \times 10^{19} \mathrm{~cm}^{-3}$. This is very close to the reported value for electron diffusion length in InGaAs of $0.4 \mu \mathrm{m}$ at a doping concentration of $2 \times 10^{19} \mathrm{~cm}^{-3}$. It should also be noted that the diffusion length is not only related to the diffusion coefficient but also to the carrier lifetime, which is highly dependent on the material quality, as well as dopant type. For example, with a carrier lifetime of only $1.6 \mathrm{ps}$ for carbon-doped InGaAs, the calculated diffusion length by using equation (5) is only $0.1 \mu \mathrm{m}$ for carbon-doped InGaAs at a doping concentration of $2 \times 10^{19} \mathrm{~cm}^{-3}$.

Using the above measured diffusion coefficient, the transit time is calculated to be approximately $0.35 \mathrm{ps}$ for a base width of $600 \AA$ and a doping concentration of $2 \times 10^{19} \mathrm{~cm}^{-3}$. By considering the carrier lifetime of zinc- and carbon-doped InGaAs measured by PL, values of $\beta$ of approximately 55 and 6 can be calculated for $\mathrm{InP} / \mathrm{InGaAs}$ HBTs with zinc- and 
Table 1. Layer structure of $\mathrm{Zn}$-doped and C-doped $\mathrm{InP} / \mathrm{InGaAs}$ HBTs.

\begin{tabular}{llr}
\hline Layer & Type & Thickness $(\AA)$ \\
\hline Emitter cap & $\mathrm{n}^{+}$-InGaAs & 2000 \\
& $\mathrm{~N}^{+}$-InP & 700 \\
Emitter & $\mathrm{N}$-InP & 1500 \\
Spacer & $\mathrm{i}$-InGaAs & 100 \\
Base & $\mathrm{p}^{+}$-InGaAs & 600 \\
Collector & $\mathrm{n}^{-}$-InGaAs & 5000 \\
Subcollector & $\mathrm{n}^{+}$-InGaAs & 5000 \\
Substrate & Semi-insulating InP $(001)$ & \\
\hline
\end{tabular}

carbon-doped bases, respectively. These results are compared with the experimental data obtained for HBTs made with zinc- and carbon-doped InGaAs materials for the bases and are discussed in the next section.

\subsection{Validation of lifetime results through experimental HBT device results}

InP/InGaAs HBT layers have been successfully grown using both zinc and carbon as p-base dopants by MOCVD. In order to study the impact of InGaAs dopants on device performance, a standard NPN InP/InGaAs HBT layer structure was used in this study (table 1). The HBTs consist of a subcollector of $5000 \AA$ uniformly doped to $2 \times 10^{19} \mathrm{~cm}^{-3}$, a collector of $5000 \AA$ lightly doped to $5 \times 10^{16} \mathrm{~cm}^{-3}$, a base of $600 \AA$, an undoped InGaAs spacer of $100 \AA$. It also employs $1500 \AA$ and $700 \AA \mathrm{InP}$ as wide-band emitter layers with doping concentrations of $5 \times 10^{17} \mathrm{~cm}^{-3}$ and $2 \times 10^{19} \mathrm{~cm}^{-3}$, respectively. Finally, a heavily doped InGaAs layer was grown to improve the ohmic contact resistance.

For InP/InGaAs HBT layer growth with zinc-doped base, all the layers were grown at $570^{\circ} \mathrm{C}$ without growth interruption except as needed for gas switching. For carbon-doped $\mathrm{InP} / \mathrm{InGaAs}$ HBTs, growth was interrupted before and after base growth to decrease and increase the growth temperature to increase the carbon incorporation efficiency. In other words, all the other layers were grown at $570{ }^{\circ} \mathrm{C}$ except for the carbondoped base, which was grown at $450{ }^{\circ} \mathrm{C}$.

The dc performance of zinc- and carbon-doped InP/InGaAs HBTs with large dimensions $\left(30 \times 30 \mu \mathrm{m}^{2}\right)$ was evaluated. Figures 11 and 12 show the dc characteristics for $\mathrm{InP} / \mathrm{InGaAs}$ HBTs with zinc- and carbon-doped base regions, respectively. As already discussed, the carrier lifetime of carbon-doped InGaAs is approximately one order of magnitude lower than that of zinc-doped InGaAs at the same doping concentration. As a result, the current gain of carbondoped HBT is considerably lower than that of zinc-doped HBT. One can see from figures 11 and 12 that the current gain of zinc-doped HBT is about five times larger than that of carbondoped HBT with the same geometry $\left(30 \times 30 \mu \mathrm{m}^{2}\right)$. A dc gain $h_{\mathrm{FE}}$ (large-signal gain) of 35 and 7 has been measured for zinc- and carbon-doped HBTs, respectively. On the other hand, differential current gain $h_{\mathrm{fe}}$ was measured to be 50 and 12, respectively, for HBTs with zinc- and carbon-doped bases. The differential current gain $h_{\mathrm{fe}}$ was larger than large-signal current gain $h_{\mathrm{FE}}$ as a result of the larger base current ideality factor than collector current ideality factor according to the

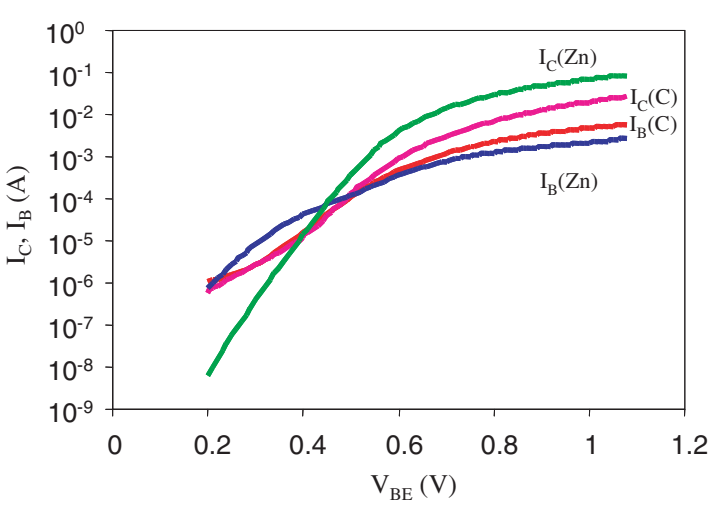

Figure 11. Gummel plot of InP/InGaAs:Zn and InP/InGaAs:C HBTs $\left(30 \times 30 \mu \mathrm{m}^{2}\right)$.

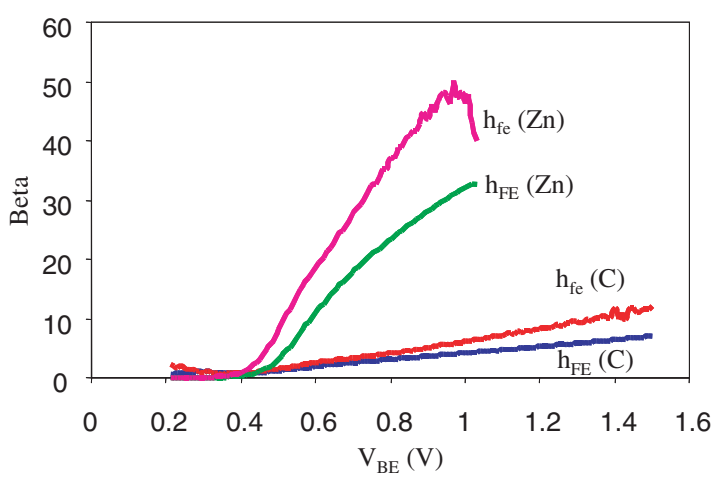

Figure 12. The dc gain as a function of $V_{\mathrm{BE}}$ for $\mathrm{InP} / \mathrm{InGaAs}: \mathrm{Zn}$ and InP/InGaAs:C HBTs $\left(30 \times 30 \mu \mathrm{m}^{2}\right)$.

following equation

$$
h_{\mathrm{fe}}=\frac{\Delta I_{\mathrm{C}}}{\Delta I_{\mathrm{B}}}=\frac{n_{\mathrm{B}}}{n_{\mathrm{C}}} \frac{I_{\mathrm{C}}}{I_{\mathrm{B}}}=\frac{n_{\mathrm{B}}}{n_{\mathrm{C}}} h_{\mathrm{FE}}>h_{\mathrm{FE}}
$$

where $n_{\mathrm{B}}$ and $n_{\mathrm{C}}$ are base current and collector current ideality factors, respectively.

These device results are close to the values predicted by carrier lifetime measurements (55 and 6) and reported in the previous discussion.

\section{Conclusions}

Heavily doped p-type InGaAs has been successfully grown by the MOCVD technique using $\mathrm{CBr}_{4}$ as a carbon precursor. A doping concentration as high as $2 \times 10^{19} \mathrm{~cm}^{-3}$ has been reached for as-grown samples. PL measurements have been used to characterize the recombination mechanisms in asgrown zinc- and carbon-doped InGaAs samples. Valence band splitting was observed for heavily strained samples. The minority carrier lifetime of as-grown carbon-doped InGaAs samples was found to be significantly lower than that of asgrown zinc-doped samples at the same doping concentration. Carrier lifetime was found to improve by optimizing the growth temperature of zinc-doped InGaAs. Zinc-doped InGaAs grown at the same temperature $\left(450{ }^{\circ} \mathrm{C}\right)$ as carbondoped samples has a higher minority carrier lifetime. Low $\mathrm{V} / \mathrm{III}$ ratio and hydrogen passivation, as well as low growth 
temperatures, are possible causes of the minority carrier lifetime difference between zinc- and carbon-doped samples. Finally, InP/InGaAs HBTs using both zinc and carbon as base dopants have been grown and fabricated. The experimental device results agree well with those predicted by the carrier lifetime measurements for zinc- and carbon-doped InGaAs samples.

\section{Acknowledgments}

This work is supported by ARO MURI (DAAH04-96-1-0001). The authors also would like to thank Dr S Krawczyk from ECL, France and Dr B Sermage from CNET, France for the helpful discussion.

\section{References}

[1] Hong K and Pavlidis D 1995 Heavily carbon doped InGaAs lattice matched to InP grown by LP-MOCVD using TMIn, TMGa and liquid $\mathrm{CCl}_{4}$ Proc. 7th IPRM (Sapporo, Japan) pp 144-7

[2] Krawczyk S K 1994 The Encyclopedia of Advanced Materials (Oxford: Pergamon) p 2318

[3] Sermage B, Benchimol J L, Michel J C, Alexandre F, Launay P and Caffin D 1996 Analysis of the uniformity of the localized area epitaxy by spectrally resolved scanning photoluminescence Proc. 8th IPRM (Schwäisch Gmund, Germany) pp 23-6

[4] Krawczyk S K and Nuban M F 1994 Room-temperature scanning photoluminescence for mapping the lifetime and the doping density in compound semiconductors Mater. Sci. Eng. B 28 452-6

[5] Krawczyk S K, Bejar M, Nuban M F, Blanchet R C, Sermage B, Benchimol J L, Hong K, Cui D and Pavlidis D 1997 New scanning photoluminescence technique for mapping the lifetime and the doping density: application to carbon doped InGaAs/InP layers and heterostructures Proc. 9th IPRM (Tsukuba, Japan) pp 525-8

[6] Chelli C, Cui D, Hubbard S M, Eisenbach A, Pavlidis D, Krawczyk S K and Sermage B 1999 Minority carrier lifetime in MOCVD-grown C- and Zn-doped InGaAs Proc. 11th IPRM (Davos, Switzerland) pp 127-30
[7] Stockman S A, Hanson A W, Colomb C M, Fresina M T, Baker J E and Stillman G E 1993 A comparison of TMGa and TEGa for low temperature metalorganic chemical vapour deposition growth of CCl4-doped InGaAs J. Electron. Mater. 23 791-9

[8] Hong K and Pavlidis D 1996 Growth and characterization of heavily carbon doped InGaAs lattice matched to InP by LP-MOCVD using liquid $\mathrm{CCl}_{4}$ J. Electron. Mater. 25 449-55

[9] Caneau C, Bhat R, Goswami S and Koza M A 1996 OMVPE grown GaInAs:C for HBTs J. Electron. Mater. 25 491-5

[10] Kuphal E, Pöcker A and Eisenbach A 1993 Relation between photoluminescence wavelength and lattice mismatch in metalorganic vapor-phase epitaxy InGaAs/InP J. Appl. Phys. 73 4599-604

[11] Asai H and Oe K 1983 Energy band-gap shift with elastic strain in $\mathrm{Ga}_{x} \mathrm{In}_{1-x} \mathrm{P}$ epitaxial layers on (001) GaAs substrates J. Appl. Phys. 54 2052-6

[12] Gaskill D K, Bottka N, Aina L and Mattingly M 1990 Band-gap determination by photoreflectance of InGaAs and InAlAs lattice matched to InP Appl. Phys. Lett. 56 1269-71

[13] Wagner G, Gottschalch V, Rhan H and Paufler P 1989 Pseudomorphic growth and nucleation of misfit dislocations in the epitaxial system (001) $\mathrm{InP} / \mathrm{In}_{1-x} \mathrm{Ga}_{x} \mathrm{As}$ : I.

Pseudomorphic growth, tetragonal distortion, and lattice relaxation by dislocation nucleation Phys. Status Solidi a 112 519-31

[14] Towe E 1982 Photoluminescence of undoped $\mathrm{In}_{0.53} \mathrm{Ga}_{0.47} \mathrm{As} / \mathrm{InP}$ grown by the vapor phase epitaxy technique J. Appl. Phys. 53 5136-9

[15] Penna A F S, Shah J and Digiobanni A E 1984 Luminescence in high purity $\operatorname{In}_{0.53} \mathrm{Ga}_{0.47}$ As Solid State Commun. $51217-20$

[16] Yu P W and Kuphal E 1984 Photoluminescence of Mn- and undoped $\mathrm{Ga}_{0.47} \mathrm{In}_{0.53}$ As on InP Solid State Commun. 49 907-10

[17] Calderon L, Lu Y, Shen H, Pamulapati J, Dutta M, Chang W H, Yang L W and Wright P D 1992 Photoluminescence characterization of nonradiative recombination in carbon-doped GaAs Appl. Phys. Lett. 60 1597-9

[18] Ambree P, Gruska B and Wandel K 1992 Dependence of the electron diffusion length in $\mathrm{p}$-InGaAs layers on the acceptor diffusion process Semicond. Sci. Technol. 7 858-60

[19] Henry C H, Logan R A, Merrit F R and Bethea C G 1984 Radiative and nonradiative lifetimes in n-type and p-type $1.6 \mu \mathrm{m}$ InGaAs Electron. Lett. 20 358-9 